\title{
Effects of Hyperbaric Oxygen on Inflammatory Response to Wound and Trauma: Possible Mechanism of Action
}

\author{
Noori S. Al-Waili* and Glenn J. Butler \\ Life Support Technologies, Inc. - New Technologies, Inc., Chronic Wound \\ Treatment and Hyperbaric Medicine Center, The Mount Vernon Hospital, 7th \\ Avenue 12 North, Mount Vernon, NY 10550
}

Received November 14, 2005; Revised March 4, 2006; Accepted March 6, 2006; Published April 3, 2006

There is growing interest in expanding the clinical applications for $\mathrm{HBO}_{2}$ (hyperbaric oxygen therapy) into new medical and surgical fields. The pathophysiology of response towards wounds, infection, trauma, or surgery involves various chemical mediators that include cytokines, prostaglandins (PGs), and nitric oxide (NO). The beneficial role played by $\mathrm{HBO}_{2}$ in wound healing, carbon monoxide poisoning, decompression sickness, and other indications is well documented. However, the exact mechanism of action is still poorly understood. This review addresses the effects of $\mathrm{HBO}_{2}$ on PGs, NO, and cytokines involved in wound pathophysiology and inflammation in particular. The results of this review indicate that $\mathrm{HBO}_{2}$ has important effects on the biology of cytokines and other mediators of inflammation. $\mathrm{HBO}_{2}$ causes cytokine down-regulation and growth factor upregulation. $\mathrm{HBO}_{2}$ transiently suppresses stimulus-induced proinflammatory cytokine production and affects the liberation of TNF $\alpha$ (tumor necrosis factor alpha) and endothelins. VEGF (vascular endothelial growth factor) levels are significantly increased with $\mathrm{HBO}_{2}$, whereas the value of PGE2 and COX-2 mRNA are markedly reduced. The effect of $\mathrm{HBO}_{2}$ on NO production is not well established and more studies are required. In conclusion, cytokines, PGs, and NO may play a major role in the mechanism of action of $\mathrm{HBO}_{2}$ and further research could pave the way for new clinical applications for $\mathrm{HBO}_{2}$ to be established. It could be proposed that chronic wounds persist due to an uncontrolled pathological inflammatory response in the wound bed and that $\mathrm{HBO}_{2}$ enhances wound healing by damping pathological inflammation (anti-inflammatory effects); this hypothetical proposal remains to be substantiated with experimental results.

KEYWORDS: hyperbaric, oxygen, nitric oxide, prostaglandin, cytokines, inflammation, wound

\section{INTRODUCTION}

Proper management of a chronic wound requires adequate oxygen delivery to the tissue, adequate protein, vitamins, minerals, nutritional factors, a moist environment, an appropriate inflammatory milieu, debridement, and correction of contributing medical diagnoses. In some patients, these conditions are achieved easily and the wound closes properly. However, in other patients, no healing can be obtained despite aggressive management of these conditions. Following injury, acute or chronic inflammation is 
evident as part of the body's defense against damaged cells and invading pathogens. The pathophysiology of responses following trauma involves various chemical mediators, which include cytokines, prostaglandins (PGs), and nitric oxide (NO) (Fig. 1).

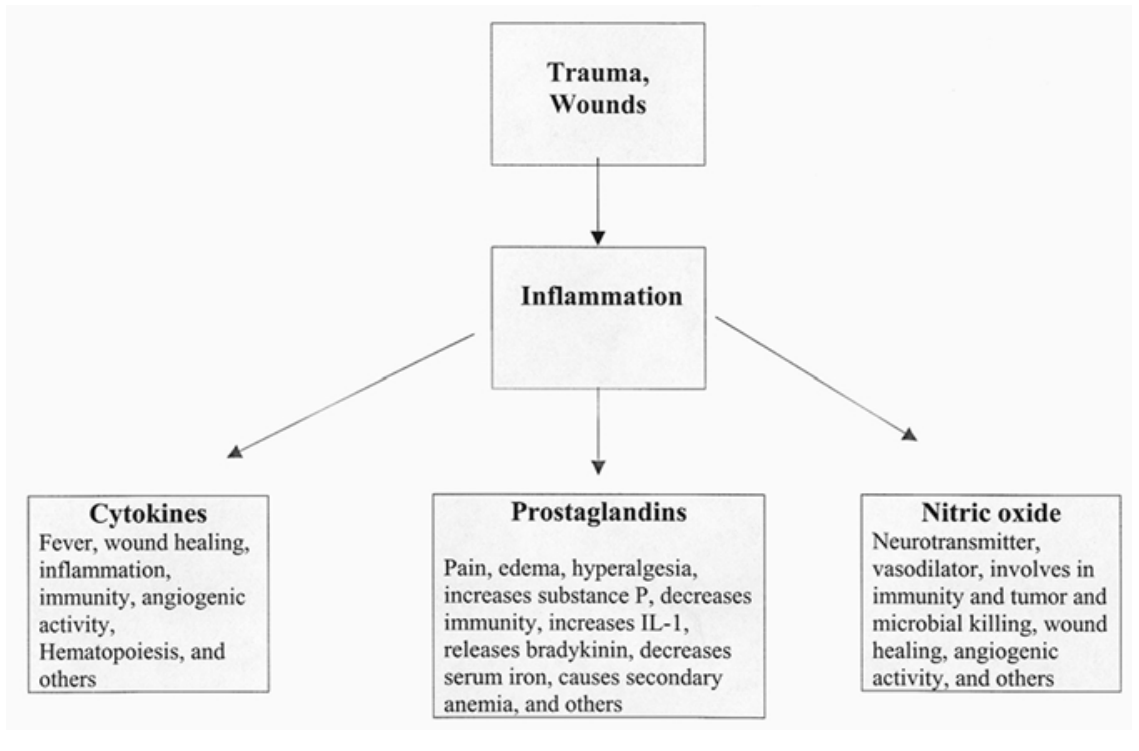

FIGURE 1. Mediators of biological response to trauma.

Current advances in adjunctive therapies such as $\mathrm{HBO}_{2}$ (hyperbaric oxygen therapy), phototherapy, and alternative medicine, have enabled improved outcomes to be achieved. There is increasing interest in the beneficial role of $\mathrm{HBO}_{2}$ in the field of wound healing $[1,2,3,4] . \mathrm{HBO}_{2}$ means breathing pure $(100 \%)$ oxygen under increased atmospheric pressure. $\mathrm{HBO}_{2}$ induces high oxygen partial pressure in all tissues, reduces edema, causes activation of fibroblasts and macrophages, and stimulates angiogenesis and collage synthesis. $\mathrm{HBO}_{2}$ chambers were originally developed at the turn of the 19th century to treat caisson workers and deep-sea divers who suffered from decompression sickness. The hyperbaric pressure can be delivered either with a monoplace chamber, which accommodates an individual patient usually in the supine position, or with a multiplace chamber, which will accommodate two or more patients. $\mathrm{HBO}_{2}$ is safe and complications are uncommon.

Rarely, acute central nervous system toxicity including seizure may occur, usually in patients with predisposing conditions such as fever, head injury, or diabetes. At the treatment pressure commonly used for elective wound care (2.4 ATA), the incidence of oxygen seizure is 1.3/10,000 treatments for all patients. Pulmonary toxicity with pulmonary fibrosis and shortness of breath, which results from chronic exposure, are rarely seen during the maximum 20-30 treatment programs used for problem wounds. In the event that a patient develops symptoms, they are reversed by stopping treatment for a few days.

$\mathrm{HBO}_{2}$ has shown promise in the management of chronic wounds. $\mathrm{HBO}_{2}$ is thought to improve many aspects of poor healing by supplying high levels of oxygen at increased atmospheric pressure. It has been suggested that increasing the availability of oxygen does not necessarily stimulate the healing process, but that perhaps the pressure at which the oxygen is delivered is the responsible stimulus. The exact mechanism that explains the beneficial effect of $\mathrm{HBO}_{2}$ on wound healing is not well understood. However, such an effect could be ascribed to the effects of $\mathrm{HBO}_{2}$ on the inflammatory and immunological mediators. This article reviews scientific works describing the influence of $\mathrm{HBO} 2$ exposure on these mediators. 


\section{CYTOKINES}

Trauma and wounds induce an inflammatory response characterized by cytokine release and neutrophil activation and microvascular adherence[5,6]. Cytokines are polypeptides or glycoproteins, produced by macrophages and T-cells, that mediate and regulate immunity, inflammation, and hematopoiesis (Table 1). They act by binding to specific membrane receptors, which then signal the cell via secondary messengers to alter its biological activity. The receptors and their corresponding cytokines have been divided into several families based on their structure and activities. These include the hematopoietin, IFN (interferon), TNF (tumor necrosis factor), and chemokine family receptors. Responses to cytokines include increasing or decreasing expression of membrane proteins (including cytokine receptors), proliferation, and secretion of effecter molecules. Cytokines act over short distances and short time spans, and at very low concentration.

Cytokine is a general name; other names include lymphokine (cytokines made by lymphocytes), monokine (cytokines made by monocytes), chemokine (cytokines with chemotactic activities), and interleukin (IL) (cytokines made by one leukocyte and acting on other leukocytes). The largest group of cytokines that stimulate immune cell proliferation and differentiation includes IL-1, IL-2, IL-3, IL-4, IL5, IL-6, IL-7, IFN $\gamma$, and granulocyte monocyte colony-stimulating factor.

IFN inhibits virus replication in infected cells and also stimulates antigen-presenting cells. Chemokines attract leukocytes to infection sites. Some cytokines, such as IL-10 and IL-12, are predominantly inhibitory and act on inflammatory cytokine production by macrophages. TNF $\alpha$ and IL-6 are proinflammatory cytokines. They enhance antimicrobial function and help tissue repair.

\section{Wound Healing and Cytokines}

Wound healing, whether initiated by trauma, microbes, or foreign objects, shows an overlapping pattern of processes that include coagulation, inflammation, epithelialization, formation of granulation tissue, and matrix and tissue remodeling. These events are the main stages of wound repair: inflammatory, proliferative, and remodeling (Fig. 2).

Neutrophils release VEGF (vascular endothelial growth factor) and IL-8, which activate endothelial cells and induce angiogenesis by a paracrine feed-forward mechanism involving endothelial IL-8 upregulation[7]. Neutrophils, however, are a rich source of proinflammatory cytokines, such as IL-8 and TNF[8]. IL-10 released from neutrophil fractions plays an active role in the development of posttraumatic immunosuppression[6] (Table 2).

The macrophages provide a continuing source of growth factors necessary to stimulate fibroplasia and angiogenesis, the fibroblasts produce the new extracellular matrix necessary to support cell in-growth, and blood vessels carry oxygen and nutrients necessary to maintain cellular metabolic process. Monocytes and macrophages express colony-stimulating factor 1, a cytokine necessary for the survival of monocytes and macrophages; TNF $\alpha$, a potent inflammatory cytokine that causes fever, granulocytosis, and chemotaxis; and PDGF (platelet-derived growth factor), a potent chemoattractant and mitogen for fibroblasts. Other important cytokines expressed by monocytes and macrophages are TGF $\alpha$ (transforming growth factor), IL-1, TGFß, and insulin-like growth factor I[9]. Growth factors, especially PDGF and TGFß1 in concert with the extracellular-matrix molecules, presumably stimulate proliferation and migration of fibroblasts of the tissue around the wound, and express appropriate integrin receptors. Indeed, PDGF accelerates the healing of chronic pressure sores[10,11,12,13,14].

Many molecules have also been found to exhibit angiogenic activity, including VEGF, TGFß, angiogenin, angiotropin, and angiopoietin $1[15,16,17]$ (Table 1). Low oxygen tension and elevated lactic acid may also stimulate angiogenesis[18]. Activated epidermal cells of the wound secrete large quantities of VEGF[19]. FGF ( fibroblast growth factor) may initiate angiogenesis during the first 3 days of wound repair, whereas VEGF plays a role in angiogenesis during the formation of granulation tissue on days 4 
through 7[20]. Proangiogenic cytokines include IL-1 and TNF, and antiangiogenic cytokines include IFN$\gamma$ and IL-12[21].

TABLE 1

\section{Cytokines and Their Functions on Wound Healing}

\section{Type of Cytokine}

Colony-stimulating factor 1

Tumor necrosis factor $\alpha$

Platelet-derived growth factor

Transforming growth factor $\beta 1$

Transforming growth factor $\beta 2$

Vascular endothelial growth factor

Angiogenin, angiotropin, angiopoietin 1 , thrombospondin

Fibroblast growth factor

IL-1

IL-1, $-2,-4,-5$, and -6

IL-10

IL-12

Colony-stimulating factor

Interferon $y$

Interferon $\alpha$

Insulin-like growth factor I

Epidermal growth factor

\section{Function}

\section{Survival of monocytes and macrophages}

Inflammatory cytokine

Activates macrophages

Stimulates angiogenesis

Stimulates synthesis of collagen and collagenase

Chemoattractant and mitogen for fibroblasts

Stimulates fibroblasts of the tissue around the wound

Accelerates the healing of chronic pressure sores

Stimulates remodeling and contraction

Chemotactic for most cells involved in wound healing

(polymorphneuclocytes, fibroblasts, macrophages, smooth muscle

cells)

Simulates angiogenesis

Activates wound healing cells

Stimulates fibroblasts of the tissue around the wound

Stimulates contraction

Attenuates ischemia-reperfusion injury

Inhibits apoptosis of myofibroblasts

Angiogenic activity

Stimulates fibroblast proliferation and the production of proteoglycans, collagen, and fibrin

Promotes accumulation of the extracellular matrix and fibrosis

Reduces scarring

Reverses the inhibition of wound healing by glucocorticoids

Induces contraction

Has angiogenic activity

Angiogenic activity

Increases vasopermeability

Angiogenic activity

Stimulates wound contraction and epithelialization and production of collagen, fibronectin, and proteoglycans

Stimulates angiogenesis

Increases chemotaxis and collagen synthesis

Stimulate macrophages and immune cells

Anti-inflammatory

Inhibits interferon and IL-2 secretion

Inhibits macrophage

Induces IL-2 production

Stimulates hematopoiesis

Stimulates macrophages and immune cells

Activates macrophages and regulates cytokines

Stimulates wound healing and fibroblast

The first cytokine described

Stimulates fibronectin synthesis, angiogenesis, fibroplasia, and

collagenase activity

Stimulates keratinocyte migration and granulation tissue development. 


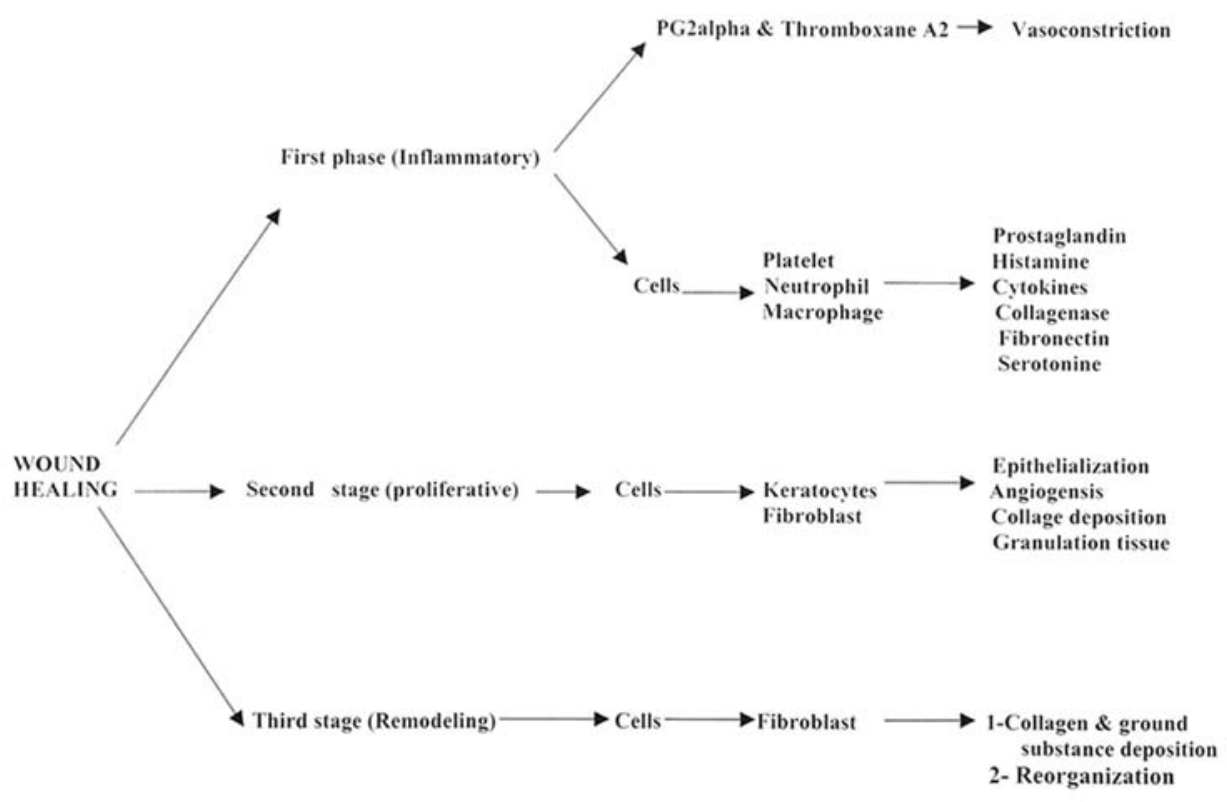

FIGURE 2. Stages of wound healing and cellular involvement.

TABLE 2

Type of Cytokines Secreted by Various Cells Involved in Wound and Inflammation

\begin{tabular}{ll}
\hline Type of Cells & \multicolumn{1}{c}{ Cytokines Released } \\
\hline Macrophages & IL-1, $-2,-6,-8,-12$ \\
& TNF \\
& FGF \\
& EGF \\
& TGFa and $\beta$ \\
& PDGF \\
& VEGF \\
Neutrophils & IL-8 \\
& IL-1ra (inhibits IL-1) \\
& TNF \\
& IL-10 \\
& PDGF \\
Platelet & TGF and $\beta$ \\
& EGF \\
Mast cell & IL-1, $-2,-6,-8$ \\
& FGF \\
Endothelial cell & PDGF \\
& TGF $\beta$ \\
& FGF \\
Lymphocyte cell & IFN $\alpha, \beta, \gamma$ \\
& IL-1, $-2,-6,-8,-10,-12$ \\
& FGF \\
Keratocyte cell & TGF and $\beta$ \\
& IL-1, $-2,-6,-8$ \\
& TGFa and $\beta$ \\
& Keratocyte growth factor \\
\hline & \\
\hline
\end{tabular}


Wound contraction probably requires stimulation by TGFß1 or $\beta 2$, and PDGF; attachment of fibroblasts to the collagen matrix through integrin receptors; and cross-links between individual bundles of collagen[22,23,24]. Blockade of $\beta 2$-integrin signaling by the addition of antibodies against the CD11b to the cultures increased IL-10 production by macrophages from injured mice[25]. $\mathrm{HBO}_{2}$ inhibits the function of human neutrophil 32 integrins by a process linked to impaired synthesis of cGMP[26].

\section{Interaction Between PG, NO, and Cytokines in Wounds and Trauma}

Various mediators such as PGs, NO, and cytokines are liberated following trauma and injury (Fig. 3). Macrophages isolated from injured mice produce higher levels of PGE2, TNF $\alpha$, IL-6, and IL-10, and lower levels of IL-12 in response to lipopolysaccharide stimulation than do cells from sham-treated mice[25]. An early response to an acute inflammatory insult, such as in wound healing, is the conversion of arginine to the cytostatic molecule $\mathrm{NO}[27]$. NO increases angiogenesis[28,29]. NO is implicated in angiogenesis induced by TGF and VEGF[30,31]. NO modulates chemoattractant cytokines including IL-8 and TGFß1[32,33]. NO stimulates the proliferation of endothelial cells, protects endothelial cells from apoptosis, and mediates VEGF production[34]. NO donors increase collagen formation in fibroblasts derived from both normal and wounded skin[35,36,37,38]. TNF $\alpha$, IFN $\gamma$, and IL-1 $\beta$ enhance NO production by inducing the inflammationassociated biosynthetic enzyme[39]. IFN $\gamma$ and IL-1 $\beta$ induce nitrite formation, and NO production and permeability; NO has been suggested to play a role in the induction of fibroblast apoptosis[40,41,42].

Exogenous PG of the E-series suppresses connective tissue proliferation[43]. COX-2 pathway plays a role in the regulation of the inflammatory phase of cutaneous wound repair[44,45]. Inhibition of this inflammatory pathway has also been suggested to reduce scar formation[44]. PGE2 augments collagen deposition and fibroblast proliferation in skin[46,47]. On other hand, PGE2 is known to reduce collagen deposition and fibroblast proliferation in the lung suggesting that PGE2 can have varied effects on cells depending on the type and origin of the cell[48,49,50]. NSAIDS, COX-1, and COX-2 inhibitors inhibit angiogenesis and delay wound and bone healing[51,52,53]. This might be due to inhibition of NO by these agents.

NO increases the activity of the COX-2 pathway in the setting of inflammatory cytokine stimulation. IL-1 $\beta$ induces PGE2 formation[42]. PGE2 and NO production are increased by TNF $\alpha$, IL-1 $\beta$, and IFN $\gamma$ [54]. Both NO and PGE2 can have effects on fibroblasts in addition to modulating the contraction of collagen gels. PGE2 is a well-described inhibitor of fibroblast proliferation[55]. The production of PGE2 and $\mathrm{NO}$ induced by cytokines can affect fibroblast numbers as well as altering their contractile behavior.

\section{$\mathrm{HBO}_{2}$ and Cytokines}

$\mathrm{HBO}_{2}$ affects the release of a number of cytokines and growth factors important to wound healing. Studies showed various effects of $\mathrm{HBO}_{2}$ on cytokine production (Table 3). $\mathrm{HBO}_{2}$ up-regulates FGF and collagen synthesis[56,57,58,59]. In patients with Crohn's disease, $\mathrm{HBO}_{2}$ diminishes IL-1, IL-6, and TNF $\alpha$ levels[60]. $\mathrm{HBO}_{2}$ effectively reduces heatstroke-induced plasma TNF $\alpha$ overproduction[61]. VEGF is upregulated by hypoxia and hyperoxia of $\mathrm{HBO}_{2}[62]$. The effects of TGF $\beta 1$ and PDGF $\beta$ are enhanced by $\mathrm{HBO}_{2}$ [63]. VEGF, TGF $\beta$, and PDGF $\beta$ have biphasic release patterns; their release is stimulated by hypoxia and hyperoxia[64,65]. The activity of released VEGF is further enhanced during hyperoxia[65].

Human blood-derived monocyte-macrophages are stimulated before being transferred to an $\mathrm{HBO}_{2}$ chamber where they were incubated in $97.9 \% \mathrm{O}_{2}, 2.1 \% \mathrm{CO}_{2}$, at 2.4 ATA. It was found that a 90-min 
$\mathrm{HBO}_{2}$ exposure inhibits IL- $1 \beta$ by $23 \%$, lipid A by $45 \%$, phytohemagglutinin A by $68 \%$, and TNF $\alpha$ by

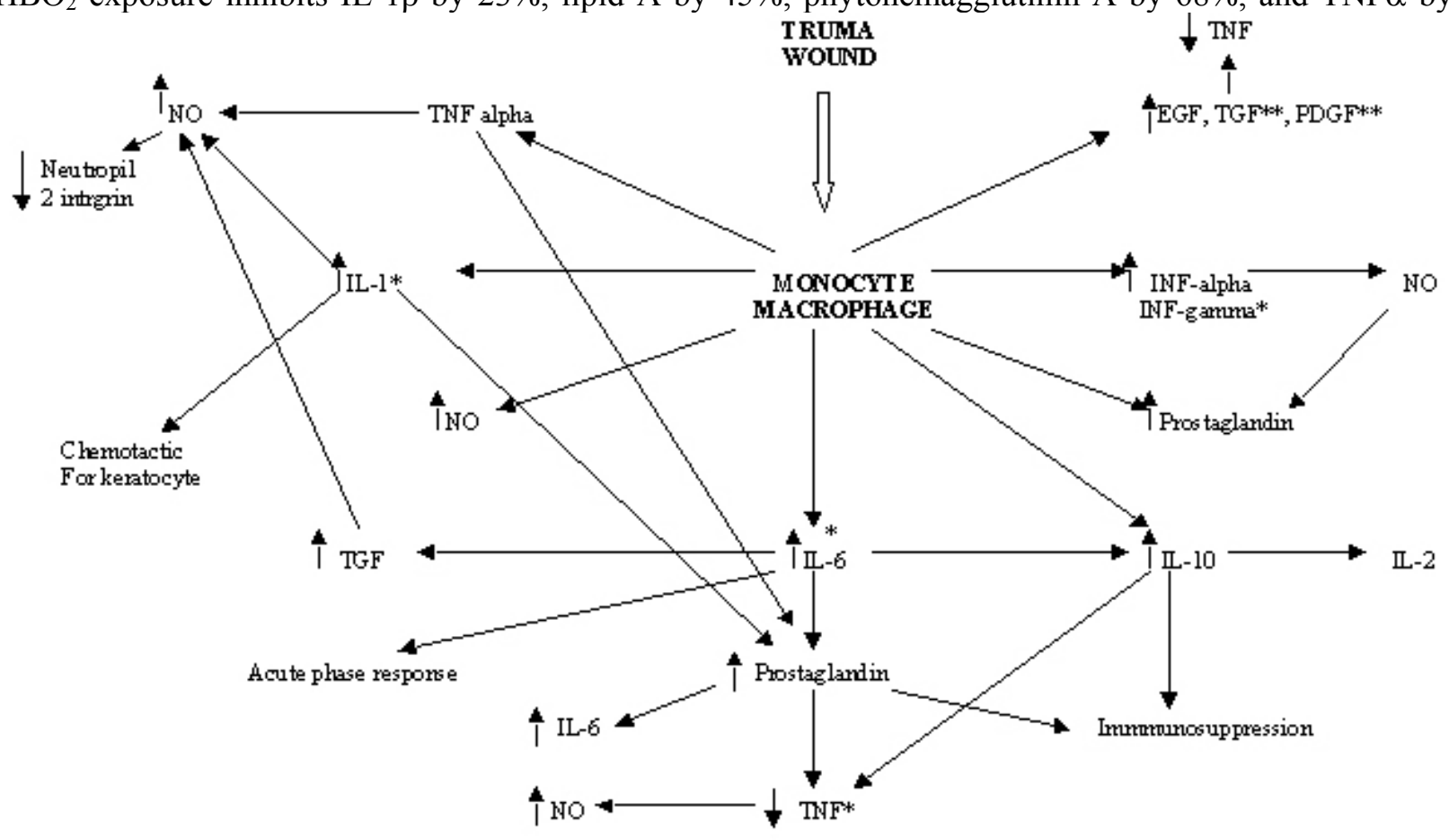

FIGURE 3. Interaction between cytokines, PGs, and NO. *Inhibited by $\mathrm{HBO}_{2} .{ }^{* *}$ Elevated by $\mathrm{HBO}_{2}$.

\section{TABLE 3}

\section{Some Effects of $\mathrm{HBO}_{2}$ on Biological Mediators of Inflammation and Wound Healing}

\section{Cytokines}

1. Enhance cytokine release

2. Decrease IFNy release from stimulated lymphocytes

3. Increase endothelin 1, vasoconstriction

4. Decrease IL-1, IL-6, TNF

5. Increase VEGF level, angiogenesis

6. Decrease TNF $\alpha$ after ischemia reperfusion

7. Up-regulate FGF

8. Enhance release of TGF $\beta 1$ and PDGF $\beta$

\section{PGs}

1. Decrease PGE2 in macrophages, bone, gingival, colitis, and kidney

2. Decrease COX-2 mRNA and protein production

3. Increase PGE2 in duodenal ulcer

NO

1. Increases NO production - increases angiogensis and inhibition of neutrophil 2-integrin function

2. Decreases NO production - causes vasoconstriction that could be prevented by ascorbic acid, superoxide dismutase, and prolonged $\mathrm{HBO}_{2}$ exposure 
$27 \% . \mathrm{HBO}_{2}$ suppresses lipopolysaccharide-, lipid A-, and phytohaemagglutinin A-induced TNF $\alpha$ by 29,31 , and $62 \%$, respectively. $\mathrm{HBO}_{2}$ exposure transiently suppresses stimulus-induced proinflammatory cytokine production[66]. Van den Blink et al. found that $\mathrm{HBO}_{2}$ enhances cytokine release of both unstimulated as well as lipopolysaccharide-challenged macrophages[67].

Another study examines the effects of hyperoxia, increased atmospheric pressure, and $\mathrm{HBO}_{2}$ on cytokine synthesis in healthy volunteers who were exposed to $90 \mathrm{~min}$ of room air, $100 \%$ oxygen, $10.5 \%$ oxygen at 2 ATA, or $100 \%$ oxygen at 2 ATA $\mathrm{HBO}_{2}$. Following the $\mathrm{HBO}_{2}$ exposure, stimulated lymphocytes released $51 \%$ less IFN $\gamma$ than cells obtained before the exposure. In addition, increased atmospheric pressure alone inhibited IFN $\gamma$ secretion while room air and hyperoxia alone had no significant effect on IFN $\gamma$ release[68]. $\mathrm{HBO}_{2}$ in healthy volunteers can induce liberation of compounds such as $\mathrm{TNF} \alpha$ and endothelins. It was suggested that liberation of endothelin 1 determines vasoconstriction occurring during $\mathrm{HBO}_{2}[69]$.

$\mathrm{HBO}_{2}$ induces neovascularization in the partial-thickness skin graft while preserving regenerative capacity in the graft boundary and normal proliferative capacity of the epidermis[70]. Sheikh et al. reported that wound oxygen rises with $\mathrm{HBO}_{2}$ from nearly $0 \mathrm{mmHg}$ to as high as $600 \mathrm{mmHg}$ [71]. The peak level occurs at the end of the 90-min treatment, and hyperoxia of lessening degree persists for approximately $1 \mathrm{~h}$. The VEGF levels significantly increase with $\mathrm{HBO}_{2}$ by approximately $40 \% 5$ days following commencement of treatment. Increased VEGF production seems to explain in part the angiogenic action of $\mathrm{HBO}_{2}$.

Treatment with $\mathrm{HBO}_{2}$ ameliorates ischemia-reperfusion injury. Ischemia-reperfusion injury after transplantation leads to decreased bcl-2, an inhibitor of the apoptosis, and increased TNF $\alpha$ levels. TGF $\beta 1$, which is enhanced by $\mathrm{HBO}_{2}$, ameliorates reperfusion injury by up-regulating bcl-2 and inhibiting TNF $\alpha$ and apoptosis of myofibroblasts[72]. $\mathrm{HBO}_{2}$, at 2 ATA every other day, causes significant increases in bcl2 and Mn-SOD immunoreactivity[73]. It was found that $\mathrm{HBO}_{2}$ attenuates the increase in the TNF $\alpha$ and lung myeloperoxidase after intestinal ischemia reperfusion[74]. The number of neutrophils sequestered in the lung is reduced in $\mathrm{HBO}_{2}$-treated rats compared to untreated rats. The results demonstrate that $\mathrm{HBO}_{2}$ inhibits TNF $\alpha$ production during intestinal ischemia reperfusion.

Although $\mathrm{HBO}_{2}$ has an immunosuppressive effect, it does not have any significant effect on phagocytotic activity[75,76,77]. However, a marked decrease in IL-1 and IL-2 production and a significant decrease in PGE2 production are observed[70,78]. IL-1 and IL-2 increase PG production. We have found that PGs are a potent immunosuppressive[79]. Therefore, the reduction of PG production may play an important role in the anti-inflammatory effect of $\mathrm{HBO}_{2}$ and may ultimately result in enhanced local or general immune system. $\mathrm{HBO}_{2}$ induces a significant increase in the spontaneous ex vivo secretion of TNF $\alpha$ by mononuclear cells from the rat blood, spleen, and lung[80]. Stimulation with lipopolysaccharides after exposure to $\mathrm{HBO}_{2}$ induces a significant increase in TNF $\alpha$ secretion by lung and spleen macrophages compared with air controls.

Pretransplant tissue cultured in $\mathrm{HBO}_{2}$ results in long-term allograft survival and the induction of systemic immune tolerance in a murine model[81]. It was shown that pretreatment of allogeneic stimulator cells with $\mathrm{HBO}_{2}$ culture results in abrogation of cytotoxic T lymphocyte activity, proliferative responses, and IFN $\gamma$ production[82]. In divers, the finding of a postdive increase in IL-6 suggests that an inflammatory response, probably created by a blood-gas interface, may be a factor in the development of DCI (decompression illness)[81]. $\mathrm{HBO}_{2}$ decreased IL-6 and might explain, in part, its beneficial effects in divers. $\mathrm{HBO}_{2}$ at 3 ATA increases the arterial oxygen tension over 2,000 $\mathrm{mmHg}$, which should provide enough oxygen to tissues, even in the total absence of hemoglobin[80]. $\mathrm{HBO}_{2}$ significantly attenuates decreases in arterial ketone body ratio after hemorrhage, with a significant reduction of mortality and cytokine induction. 


\section{NITRIC OXIDE}

NO plays important roles in diverse physiological and pathological processes, such as neurotransmission, vasodilatation, immunological response, wound repair, tumerogenesis, and inhibition of platelet aggregation $[83,84]$. NO has been proposed as a possible active agent for enhancing wound healing. In addition, NO increases cytosolic concentration of free calcium ions and it affects functions of various enzymes[84,85,86,87]. The activity of inducible NOS (nitric oxide synthase) is controlled at the level of gene transcription, whereas the activities of neuronal NOS and endothelial NOS are controlled by intracellular calcium/calmodulin, several different phosphorylation mechanisms, and by binding of the molecular chaperone heat shock protein 90. Low-molecular-weight thiols, albumin and hemoglobin, can carry NO in the blood stream $[88,89,90]$.

\section{NO and Oxygen}

Clinical experience with adjunctive $\mathrm{HBO}_{2}$ therapy in the treatment of diabetic ulcers has shown that wound hyperoxia increases wound granulation, tissue formation, and accelerates wound contraction and closure. In addition to wound hyperoxia, increased wound NO production also appears to be important for successful diabetic wound healing. The impact of elevated $\mathrm{O}_{2}$ tension on NO synthesis has not been clearly established by clinical studies. The possible elevation of NO concentration due to hyperoxia may contribute to the augmentation of angiogenesis and inhibition of neutrophil 2-integrin function that have been reported with $\mathrm{HBO}_{2}$ [91]. Endothelial cells, however, release superoxide anion, which is converted to $\mathrm{H}_{2} \mathrm{O}_{2}$ or reacts with $\mathrm{NO}$ to generate the strong oxidant, peroxynitrite. By reacting rapidly with NO, extracellular $\mathrm{O}_{2}$ should decrease biologically available NO, which diffuses from the endothelium, erythrocytes, and vascular nerves to smooth muscle. Removal of $\mathrm{O}_{2}$ from endothelial cells should prevent inactivation of $\mathrm{NO}$ by $\mathrm{O}_{2}$ and increases its availability for vasodilation. Superoxide dismutase attenuates the degradation of NO.

Hyperoxic vasoconstriction is mediated by oxidative stress, which could be inhibited by vitamin $\mathrm{C}$ [92]. Elevated $\mathrm{O}_{2}$ tensions above ambient will increase $\mathrm{NO}$ production by pulmonary endothelial cells and intact lungs[93,94,95]. In contrast, $\mathrm{O}_{2}$ tensions above $\sim 55 \mathrm{mmHg}$ were reported to have little effect on NO production by cells obtained from the systemic circulation[96]. Furthermore, studies have demonstrated that hypoxic conditions diminish synthesis of NO in cells from both pulmonary and systemic circulations[93,94,97].

\section{Oxygen and Vasoconstriction}

High arterial blood oxygen causes vasoconstriction in healthy humans[98,99,100]. Although hyperoxic vasoconstriction was first reported at least 90 years ago[98], the mechanism for this phenomenon in healthy humans is poorly understood. Several animal models of hyperoxic vasoconstriction suggest that $\mathrm{O}_{2}$ tension may influence one or more of the endothelium-derived factors, such as NO, endothelin, and vasoactive PG[101,102,103]. It has been demonstrated that both hyperoxia and oxidative stress may stimulate increased production of the endothelium-derived vasoconstrictor endothelin[101,104].

\section{$\mathrm{HBO}_{2}$ and NO}

Previous studies have reported modulation of NOS activity by oxygen tension both in vitro and in vivo (Table 3). Pretreatment has beneficial hemodynamic effects in rats with endotoxin shock[94,105,106,107]. The beneficial effects of $\mathrm{HBO}_{2}$ may be partially mediated by decreased $\mathrm{NO}$ production via reduced lipopolysaccharide-induced lung iNOS expression[108]. Another study used in vivo microdialysis to 
investigate the formation of oxygen-free radicals and $\mathrm{NO}$ in rat's brains under $\mathrm{HBO}_{2}$ conditions. Male Sprague-Dawley rats exposed to $100 \% \mathrm{O}_{2}$ at a pressure of 3 ATA for $2 \mathrm{~h}$, showed a six- and fourfold increase in nitrite/nitrate, in hippocampal and striatal dialysates, respectively. This increase was completely blocked by the NOS inhibitor L-nitroarginine methyl ester[109].

Another study demonstrates that exposures of rodents to oxygen at pressures of 2.0 and 2.8 ATA stimulates neuronal NOS and significantly increases steady-state NO concentration[110]. These studies demonstrate an increase in $\mathrm{NO}$ levels in response to $\mathrm{HBO}_{2}$ treatment. One possible mechanism by which $\mathrm{HBO}_{2}$ results in this increase is by increasing oxygen availability. The authors reported an increase in brain tissue $\mathrm{pO}_{2}$ levels in response to $\mathrm{HBO}_{2}$ treatment[111,112]. An increase in oxygen levels under $\mathrm{HBO}_{2}$ conditions may, therefore, be a factor in increasing NO production under these conditions. Neuronal NOS activity contributes over $90 \%$ to total NO elevation due to hyperoxia. Cerebral cortex blood flow, measured by laser Doppler flow probe, is increased during hyperoxia and may be related to elevations of steady-state NO concentration[88]. It was found that relative lack of NO activity contributes to decreased cerebral blood flow under $\mathrm{HBO}_{2}$, but, as exposure time is prolonged, $\mathrm{NO}$ production increases and augments regional cerebral blood flow[113].

It is well known that $\mathrm{HBO}_{2}$ induces vasoconstriction in systemic organs, including the brain[114]. It was hypothesized that the cerebral blood flow is reduced by $\mathrm{HBO}_{2}$ because of the inactivation of NO by superoxide anions[115]. Hyperbaric vasoconstriction was diminished after NO inhibition. Intravenous injection of superoxide dismutase increased the cerebral blood flow during air and $\mathrm{HBO}_{2}$ exposure. These data suggest that inactivation of $\mathrm{NO}$ by superoxide anion is an effective mechanism of $\mathrm{HBO}_{2}$ vasoconstriction[116]. The decreases in cerebral blood flow with $\mathrm{HBO}_{2}$ are associated with a decrease in effective NO concentration and an increase in ROS(reactive oxygen species) production in the brain[116]. Studies on the central nervous system, however, have shown that an elevated partial pressure of $\mathrm{O}_{2}$ increases concentration of $\mathrm{NO}$ by stimulating neuronal NOS activity[117]. Furthermore, prolonged $\mathrm{HBO}_{2}$ exposure promotes NO production, which augments cerebral blood flow[88]. It has been shown that $\mathrm{HBO}_{2}$ significantly inhibits the increase in plasma TNF $\alpha$ and NO induced by lipopolysaccharide treatment. $\mathrm{HBO}_{2}$ corrects stress-impaired dermal wound healing and decreases iNOS expression associated with stress[118].

\section{PROSTAGLANDINS}

PGs comprise a diverse family of lipid autocoids derived from cyclooxygenase-mediated metabolism of arachidonic acid, generating five primary bioactive prostanoids: PGE2, PGF2 $\alpha$, PGD2, PGI2, and thromboxane A2. The families of PGs and ILs are called eicosanoids. Cell membranes' phospholipids are converted to arachidonic acid by phospholipase A2. Lipoxgenase converts arachidonic acid to ILs; cyclooxygenase converts arachidonic acid to PGs; while epoxygenase converts arachidonic acid to DHETs(dihydroxyeicosatrienoic acid). PGs cause inflammatory pain, edema, and hyperalgesia; increase IL-6 production; increase NO production; cause release of tachykinine and increased substance P. PGs increased in the cells by direct interaction between NO and PGHs. They are generated in response to injury and inflammation and can sensitize or directly activate sensory endings of nociceptions.

It was found that the value of PGE2 in alveolar bone and gingiva is reduced markedly after $\mathrm{HBO}_{2}$ exposure[119]. $\mathrm{HBO}_{2}$ treatment causes a marked decrease in IL-1 production and a significant decrease in PGE2 production produced by splenic macrophages[78]. A marked inhibition of renal PGE2 excretion associated with antiduresis effects during $\mathrm{HBO}_{2}$ has been observed in a conscious $\operatorname{dog}[120]$.

The effect of $\mathrm{HBO}_{2}$ on COX-2 expression after transient brain focal ischemia was evaluated. $\mathrm{HBO}_{2}$ at 3 ATA for $1 \mathrm{~h}$ was administered at $6 \mathrm{~h}$ after reperfusion. The results showed that $\mathrm{HBO}_{2}$ applied at $6 \mathrm{~h}$ after reperfusion significantly reduces infarct area as compared with a no-treatment group. $\mathrm{HBO}_{2}$ decreases COX-2 mRNA and protein levels, which were up-regulated after ischemia reperfusion. Intervention with $\mathrm{HBO}_{2}$ within $6 \mathrm{~h}$ reduces infarction[121]. 
The effect of a previous exposure to $\mathrm{HBO}_{2}$ on the synthesis capacity of PGs and thromboxane was investigated in male rats' brains. Low-level hyperoxia significantly reduces the release of 6-keto-PGF1 $\alpha$ and PGE2 in the striatum, without change in thromboxane $\mathrm{B} 2[122]$. Treatment by $\mathrm{HBO}_{2}$ was accompanied by a significant decrease in colonic weight, PGE2 generation, myeloperoxidase, and NOS activities in experimental colitis[123]. PGE levels were measured in duodenal ulcer patients treated by $\mathrm{H} 2$-blockers of histamine receptors and $\mathrm{HBO}_{2}$. Histadyl causes a marked decrease in gastric juice PGE concentrations in contrast to $\mathrm{HBO}_{2}$ that raised PGE levels close to normal values[124].

\section{$\mathrm{HBO}_{2}$ AND INFLAMMATION}

The effect of $\mathrm{HBO}_{2}$ on inflammation was studied experimentally in the treatment of experimental uveitis induced in rabbits[125]. The number of inflammatory cells and protein levels in the aqueous humor were reduced with use of $\mathrm{HBO}_{2}$. Further, it was found that $\mathrm{HBO}_{2}$ was comparable to corticosteroids in reducing inflammation. Animal studies of $\mathrm{HBO}_{2}$ have shown that $\mathrm{HBO}_{2}$ reduces infarct size and improving neurologic outcome, and inhibits inflammation and apoptosis after cerebral ischemia[126]. $\mathrm{HBO}_{2}$ reduces ulcer depth and vascular thrombosis, and mortality in animals exposed to causative agent for esophageal injury[127]. $\mathrm{HBO}_{2}$ ameliorates inflammatory changes and decreases dilatation of the intestine in animals subjected for muconeum peritonitis[128]. $\mathrm{HBO}_{2}$ ameliorates the macroscopic damage and decreases plasma carbonyl content in trinitrobenzene sulfonic acid-induced chronic colitis in rats while it significantly reduces tissue myeloperoxidase activity in acute colitis[129]. $\mathrm{HBO}_{2}$ markedly reduces the carrageenan-induced paw edema in rats by displaying anti-inflammatory activity[130]. In benign prostatic hyperplasia associated with inflammation, $\mathrm{HBO}_{2}$ was found to be effective[131]. In severe acute pancreatitis, $\mathrm{HBO}_{2}$ alleviates high spiking fever, improves white blood cell count and serum amylase levels, and reduces the abscess size[132]. Recently, we have found that $\mathrm{HBO}_{2}$ helps to reduce edema and inflammation in compartment syndrome[133]. HBO2 had pulmonary protective effects during acute necrotizing pancreatitis[134]. These studies confirm preliminarily that $\mathrm{HBO} 2$ might possess antiinflammatory properties.

\section{CONCLUSION}

Studies on the effects of $\mathrm{HBO}_{2}$ on inflammatory mediators may not only explain its mechanism of action, but also expand its clinical application. The main conclusion of this review is:

1. The angiogenic action of $\mathrm{HBO}_{2}$ may be a result of increased VEGF and NO production.

2. The immunosuppressive effect of $\mathrm{HBO}_{2}$ may be due to reduction of IL-1 production.

3. The anti-inflammatory effect of $\mathrm{HBO}_{2}$ may be due to inhibition of IFN $\gamma$, PGs, TNF $\alpha$, IL-1, and IL-6.

4. The beneficial effect on ischemia-reperfusion injury may be due to up-regulation of bcl-2 and TGF and reduction of neutrophil 2-integrin.

5. $\mathrm{HBO}_{2}$ may stimulate local and general immunity because it decreases PGs, IL-1, and IL-10.

6. Vasoconstriction may be due to inhibition of $\mathrm{NO}$ and liberation of endothelin.

7 The anti-inflammatory effect of $\mathrm{HBO}_{2}$ may stimulate the use of $\mathrm{HBO}_{2}$ in acute or chronic inflammatory diseases in which large amounts of PGs are produced.

8. $\mathrm{HBO}_{2}$ raises PGE levels close to normal values in patients with duodenal ulcer. This may encourage the use of $\mathrm{HBO}_{2}$ in patients with duodenal or gastric ulcer.

Generally, the final conclusion regarding effects of $\mathrm{HBO}_{2}$ on various mediators of inflammation is not fully documented and waits further clinical and laboratory investigation. Absolutely, conclusive results could pave the way for new applications of $\mathrm{HBO}_{2}$. 


\section{REFERENCES}

1. Al-Waili, N., Butler, G., Beale, J., Abdullah, M., Hamilton, R., Lee, B., and Lucas, P. (2005) Hyperbaric oxygen for cerebral stroke, brain trauma and neurological diseases: a promising future application. Adv. Ther. 22, 659-678.

2. Al-Waili, N., Butler, G., Beale, J., Hamilton, R., Lee, B., and Lucas, P. (2005) Hyperbaric oxygen and malignancies: a potential role in radiotherapy, chemotherapy, tumor surgery and phototherapy. Med. Sci. Monit. 11, RA279-289.

3. Roeckl-Wiedmann, I., Bennett, M., and Kranke, P. (2005) Systematic review of hyperbaric oxygen in the management of chronic wounds. Br. J. Surg. 92, 24-32.

4. Greensmith, J.E. (2004) Hyperbaric oxygen therapy in extremity trauma. J. Am. Acad. Orthop. Surg. 12, 376-384.

5. Menger, M.D. and Vollmar, B. (2004) Surgical trauma: hyperinflammation versus immunosuppression?. Langenbecks Arch. Surg. 389, 475-484.

6. Koller, M., Clasbrummel, B., Kollig, E., Hahn, M.P., and Muhr, G. (1998) Major injury induces increased production of interleukin-10 in human granulocyte fractions. Langenbecks Arch. Surg. 383, 460-465.

7. Schruefer, R., Lutze, N., Schymeinsky, J., and Walzog, B. (2005) Human neutrophils promote angiogenesis by a paracrine feedforward mechanism involving endothelial interleukin-8. Am. J. Physiol. Heart Circ. Physiol. 288, H1186-1192.

8. Zallen, G., Moore, E.E., Johnson, J.L., Tamura, D.Y., Aiboshi, J., Biffl, W.L., and Silliman, C.C. (1999) Circulating postinjury neutrophils are primed for the release of proinflammatory cytokines. J. Trauma 46(1), 42-48.

9. Rappolee, D.A., Mark, D., Banda, M.J., and Werb, Z. (1988) Wound macrophages express TGF- $\alpha$ and other growth factors in vivo: analysis by mRNA phenotyping. Science 241, 708-712.

10. Heldin, C.-H. and Westermark, B. (1996) Role of platelet-derived growth factor in vivo. In The Molecular and Cellular Biology of Wound Repair. 2nd ed. Clark, R.A.F., Ed. Plenum Press, New York. pp. 249-273.

11. Roberts, A.B. and Sporn, M.B. (1996) Transforming growth factor- $\beta$. In The Molecular and Cellular Biology of Wound Repair. 2nd ed. Clark, R.A.F., Ed. Plenum Press, New York. pp. 275-308.

12. Gray, A.J., Bishop, J.E., Reeves, J.T., and Laurent, G.J. (1993) A $\alpha$ and Bß chains of fibrinogen stimulate proliferation of human fibroblasts. J. Cell Sci. 104, 409-413.

13. Xu, J. and Clark, R.A.F. (1996) Extracellular matrix alters PDGF regulation of fibroblast integrins. J. Cell Biol. 132, 239-249.

14. Robson, M.C., Phillips, L.G., Thomason, A., Robson, L.E., and Pierce, G.F. (1992) Platelet-derived growth factor BB for the treatment of chronic pressure ulcers. Lancet 339, 23-25.

15. Folkman, J. and D'Amore, P.A. (1996) Blood vessel formation: what is its molecular basis? Cell 87, $1153-1155$.

16. Iruela-Arispe, M.L. and Dvorak, H.F. (1997) Angiogenesis: a dynamic balance of stimulators and inhibitors. Thromb. Haemost. 78, 672-677.

17. Risau, W. (1997) Mechanisms of angiogenesis. Nature 386, 671-674.

18. Detmar, M., Brown, L.F., and Berse, B. (1997) Hypoxia regulates the expression of vascular permeability factor/vascular endothelial growth factor (VPF/VEGF) and its receptors in human skin. J. Invest. Dermatol. 108, 263268.

19. Brown, L.F., Yeo, K.-T., and Berse, B. (1992) Expression of vascular permeability factor (vascular endothelial growth factor) by epidermal keratinocytes during wound healing. J. Exp. Med. 176, 1375-1379.

20. Nissen, N.N., Polverini, P.J., Koch, A.E., Volin, M.V., Gamelli, R.L., and DiPietro, L.A. (1998) Vascular endothelial growth factor mediates angiogenic activity during the proliferative phase of wound healing. Am. J. Pathol. 152, 14451452.

21. Naldini, A. and Carraro, F. (2005) Role of inflammatory mediators in angiogenesis. Curr. Drug Targets Inflamm. Allergy 4(1), 3-8.

22. Montesano, R. and Orci, L. (1988) Transforming growth factor- $\beta$ stimulates collagen-matrix contraction by fibroblasts: implications for wound healing. Proc. Natl. Acad. Sci. U. S. A. 85, 4894-4897.

23. Clark, R., Folkvord, J., Hart, C., Murray, M., and McPherson, J. (1989) Platelet isoforms of platelet-derived growth factor stimulate fibroblasts to contract collagen matrices. J. Clin. Invest. 84, 1036-1040.

24. Schiro, J.A., Chan, B.M.C., Roswit, W.T., et al. (1991) Integrin a2ß1 (VLA-2) mediates reorganization and contraction of collagen matrices by human cells. Cell 67, 403-410.

25. Schwacha, M.G., Chaudry, I.H., and Alexander, M. (2003) Regulation of macrophage IL-10 production postinjury via beta2 integrin signaling and the P38 MAP kinase pathway. Shock 20, 529-535.

26. Thom, S.R., Mendiguren, I., Hardy, K., Bolotin, T., Fisher, D., Nebolon, M., and Kilpatrick, L. (1997) Inhibition of human neutrophil beta2-integrin-dependent adherence by hyperbaric O2. Am. J. Physiol. 272(3 Pt 1), C770-777.

27. Satriano, J. (2004) Arginine pathways and the inflammatory response: interregulation of nitric oxide and polyamines: review article. Amino Acids 26, 321-329.

28. Donnini, S. and Ziche, M. (2002) Constitutive and inducible nitric oxide synthase: role in angiogenesis. Antioxid. Redox Signal. 4, 817-823.

29. Murohara, T., Asahara, T., Silver, M., Bauters, C., Masuda, H., and Kalka, C. (1998) Nitric oxide synthase modulates angiogenesis in response to tissue ischemia. J. Clin. Invest. 101, 2567-2578.

30. Morbidelli, L., Chang, C.H., Douglas, J.G., Granger, H.J., Ledda, F., and Ziche, M. (1996) Nitric oxide mediates mitogenic effect of VEGF on coronary venular endothelium. Am. J. Physiol. 270, H411-415. 
31. Roberts, A.B., Sporn, M.B., Assoian, R.K., Smith, J.M., Roche, N.S., and Wakefield, L.M. (1986) Transforming growth factor type beta: rapid induction of fibrosis and angiogenesis in vivo and stimulation of collagen formation in vitro. Proc. Natl. Acad. Sci. U. S. A. 83, 4167-4171.

32. Andrew, P.J., Harant, H., and Lindley, I.J. (1995) Nitric oxide regulates IL-8 expression in melanoma cells at the transcriptional level. Biochem. Biophys. Res. Commun. 214, 949-956.

33. Malik, A.A., Radhakrishnan, N., Reddy, K., Smith, A.D., and Singhal, P.C. (2002) Tubular cell-Escherichia coli interaction products modulate migration of monocytes through generation of transforming growth factor-beta and macrophage-monocyte chemoattractant protein-1. J. Endourol. 16, 599-603.

34. Frank, S., Kampfer, H., Wetzler, C., and Pfeilschifter, J. (2002) Nitric oxide drives skin repair: novel functions of an established mediator. Kidney Int. 61, 882-888.

35. Shi, H.P., Efron, D.T., Most, D., Tantry, U.S., and Barbul, A. (2000) Supplemental dietary arginine enhances wound healing in normal but not inducible nitric oxide synthase knockout mice. Surgery 128, 374-378.

36. Schaffer, M.R., Tantry, U., Gross, S.S., Wasserburg, H.L., and Barbul, A. (1996) Nitric oxide regulates wound healing. J. Surg. Res. 63, 237-240.

37. Thornton, F.J., Schaffer, M.R., Witte, M.B., Moldawer, L.L., MacKay, S.L., and Abouhamze, A. (1998) Enhanced collagen accumulation following direct transfection of the inducible nitric oxide synthase gene in cutaneous wounds. Biochem. Biophys. Res. Commun. 246, 654-659.

38. Schaffer, M.R., Efron, P.A., Thornton, F.J., Klingel, K., Gross, S.S., and Barbul, A. (1997) Nitric oxide, an autocrine regulator of wound fibroblast synthetic function. J. Immunol. 158, 2375-2381.

Dwyer-Nield, L.D., Srebernak, M.C., Barrett, B.S., Ahn, J., Cosper, P., Meyer, A.M., Kisley, L.R., Bauer, A.K., Thompson, D.C., and Malkinson, A.M. (2005) Cytokines differentially regulate the synthesis of prostanoid and nitric oxide mediators in tumorigenic versus non-tumorigenic mouse lung epithelial cell lines. Carcinogenesis 26(7), 11961206.

40. Zhang, H.Y., Gharaee-Kermani, M., and Phan, S.H. (1997) Regulation of lung fibroblast alpha-smooth muscle actin expression, contractile phenotype, and apoptosis by IL-1beta. J. Immunol. 158, 1392-1399.

41. Chavez, A.M., Menconi, M.J., Hodin, R.A., and Fink, M.P. (1999) Cytokine-induced intestinal epithelial hyperpermeability: role of nitric oxide. Crit. Care Med. 27(10), 2246-2251.

42. Watkins, D.N., Garlepp, M.J., and Thompson, P.J. (1997) Regulation of the inducible cyclo-oxygenase pathway in human cultured airway epithelial (A549) cells by nitric oxide. Br. J. Pharmacol. 121(7), 1482-1488.

43. Arend, A., Aunapuu, M., Masso, R., and Selstam, G. (2005) Prostaglandins of the E-series inhibit connective tissue proliferation in the liver wound of the rat. Ann. Anat. 187(1), 57-62.

44. Wilgus, T.A., Vodovotz, Y., Vittadini, E., Clubbs, E.A., and Oberyszyn, T.M. (2003) Reduction of scar formation in full-thickness wounds with topical celecoxib treatment. Wound Repair Regen. 11, 25-34.

45. Muscara, M.N., McKnight, W., Asfaha, S., and Wallace, J.L. (2000) Wound collagen deposition in rats: effects of an NO-NSAID and a selective COX-2 inhibitor. Br. J. Pharmacol. 129, 681-686.

46. Lupulescu, A. (1975) Effect of prostaglandins on protein RNA, DNA and collagen synthesis in experimental wounds. Prostaglandins 10, 573-579.

47. Durant, S., Duval, D., and Homo-Delarche, F. (1989) Effect of exogenous prostaglandins and nonsteroidal antiinflammatory agents on prostaglandin secretion and proliferation of mouse embryo fibroblasts in culture. Prostaglandins Leukot. Essent. Fatty Acids 38, 1-8.

48. McAnulty, R.J., Hernandez-Rodriguez, N.A., Mutsaers, S.E., Coker, R.K., and Laurent, G.J. (1997) Indomethacin suppresses the anti-proliferative effects of transforming growth factor-beta isoforms on fibroblast cell cultures. Biochem. J. 321, 639-643.

49. Korn, J.H., Halushka, P.V., and LeRoy, E.C. (1980) Mononuclear cell modulation of connective tissue function: suppression of fibroblast growth by stimulation of endogenous prostaglandin production. J. Clin. Invest. 65, 543-554.

50. Goldstein, R.H. and Polgar, P. (1982) The effect and interaction of bradykinin and prostaglandins on protein and collagen production by lung fibroblasts. J. Biol. Chem. 257, 8630-8633.

51. Giannoudis, P. and MacDonald, D. (2000) Nonunion of the femoral diaphysis. The influence of reaming and nonsteroidal anti-inflammatory drugs. J. Bone Joint Surg. Br. 82, 655-658.

52. Jones, M.K. and Wang, H. (1999) Inhibition of angiogenesis by nonsteroidal anti-inflammatory drugs: insight into mechanisms and implications for cancer growth and ulcer healing. Nat. Med. 5, 1418-1423.

53. Dvivedi, S. and Tiwari, S.M. (1997) Effect of ibuprofen and diclofenac sodium on experimental would healing. Indian J. Exp. Biol. 35(11), 1243-1245.

54. Zhu, Y.K., Liu, X.D., Skold, M.C., Umino, T., Wang, H., Romberger, D.J., Spurzem, J.R., Kohyama, T., Wen, F.Q., and Rennard, S.I. (2001) Cytokine inhibition of fibroblast-induced gel contraction is mediated by PGE(2) and NO acting through separate parallel pathways. Am. J. Respir. Cell Mol. Biol. 25(2), 245-253.

55. Elias, J.A. (1988) Tumor necrosis factor interacts with interleukin-1 and interferon to inhibit fibroblast proliferation via fibroblast prostaglandin-dependent and -independent mechanisms. Am. Rev. Respir. Dis. 138, 652-658.

56. Ishii, Y., Myanaga, Y., Shimojo, H., Ushida, T., and Tateishi, T. (1999) Effects of hyperbaric oxygen on procollagen messenger RNA levels and collagen synthesis in the healing of rat tendon laceration. Tissue Eng. 5, 279-286.

57. Bonomo, S.R., Davidson, J.D., Yu, Y., Xia, Y., Lin, X., and Mustoe, T.A. (1998) Hyperbaric oxygen as a signal transducer: upregulation of platelet derived growth factor-beta receptor in the presence of HBO2 and PDGF. 
Undersea Hyperb. Med. 25(4), 211-216.

58. Bayati, S., Russell, R.C., and Roth, A.C. (1998) Stimulation of angiogenesis to improve the viability of prefabricated flaps. Plast. Reconstr. Surg. 101(5), 1290-1295.

59. Wu, L., Pierce, G.F., Ladin, D.A., Zhao, L.L., Rogers, D., and Mustoe, T.A. (1995) Effects of oxygen on wound responses to growth factors: Kaposi's FGF, but not basic FGF stimulates repair in ischemic wounds. Growth Factors 12(1), 29-35.

60. Weisz, G., Lavy, A., Adir, Y., Melamed, Y., Rubin, D., Eidelman, S., and Pollack, S. (1997) Modification of in vivo and in vitro TNF-alpha, IL-1, and IL-6 secretion by circulating monocytes during hyperbaric oxygen treatment in patients with perianal Crohn's disease. J. Clin. Immunol. 17(2), 154-159.

61. Tsai, H.M., Gao, C.J., Li, W.X., Lin, M.T., and Niu, K.C. (2005) Resuscitation from experimental heatstroke by hyperbaric oxygen therapy. Crit. Care Med. 33, 813-818.

62. Hunt, T.K. (2000) Oxygen and wound healing. In Hyperbaric Medicine, 8th Annual Advanced Symposium. Palmetto Richland Memorial Hospital and the University of South Carolina School of Medicine, Columbia, SC.

63. Zhao, L.L., Davidson, J.D., Wee, S.C., Roth, S.I., and Mustoe, T.A. (1994) Effect of hyperbaric oxygen and growth factors on rabbit ear ischemic ulcers. Arch. Surg. 129, 1043-1049.

64. Gleadle, J.M. and Ratcliffe, P.J. (1998) Hypoxia and the regulation of gene expression. Mol. Med. Today 4, $122-129$.

65. Haroon, Z.A., Raleigh, J.A., Greenberg, C.S., and Dewhirst, M.W. (2000) Early wound healing exhibits cytokine surge without evidence of hypoxia. Ann. Surg. 231, 137-147.

66. Benson, M., Minter, M., Osborne, B., and Granowitz, E. (2003) Hyperbaric oxygen inhibits stimulus-induced proinflammatory cytokine synthesis by human blood-derived monocyte-macrophages. Clin. Exp. Immunol. 134, 5762.

67. van den Blink, B., van der Kleij, A., Versteeg, H., and Peppelenbosch, M.P. (2002) Immunomodulatory effect of oxygen and pressure. Comp. Biochem. Physiol. A Mol. Integr. Physiol. 132, 193-197.

68. Granowitz, E., Skulsky, E., Benson, R.M., Wright, J., Garb, J., Cohen, E., Smithline, E., and Brown, R. (2002) Exposure to increased pressure or hyperbaric oxygen suppresses interferon-gamma secretion in whole blood cultures of healthy humans. Undersea Hyperb. Med. 29, 216-225.

69. Rocco, M., Antonelli, M., Letizia, V., Alampi, D., Spadetta, G., Passariello, M., Conti, G., Serio, P., and Gasparetto, A. (2001) Lipid peroxidation, circulating cytokine and endothelin 1 levels in healthy volunteers undergoing hyperbaric oxygenation. Minerva Anestesiol. 67, 393-400.

70. Kalns, J., Dick, E.J., Jr., Scruggs, J., Kieswetter, K., and Wright, J. (2003) Hyperbaric oxygen treatment prevents upregulation of angiogenesis following partial-thickness skin grafts in the pig. Wound Repair Regen. 1, 139-144.

71. Sheikh, A., Gibson, J., Rollins, M., Hopf, H., Hussain, Z., and Hunt, T. (2000) Effect of hyperoxia on vascular endothelial growth factor levels in a wound model. Arch. Surg. 135, 1293-1297.

72. Grunenfelder, J., Miniati, D., Murata, S., Falk, V., Hoyt, E., and Robbins, R. (2002) Up-regulation of Bcl-2 through hyperbaric pressure transfection of TGF-betal ameliorates ischemia-reperfusion injury in rat cardiac allografts. $J$. Heart Lung Transplant. 21, 244-250.

73. Wada, K., Miyazawa, T., Nomura, N., Yano, A., Tsuzuki, N., Nawashiro, H., and Shima, K. (2000) Mn-SOD and Bcl-2 expression after repeated hyperbaric oxygenation. Acta Neurochir. Suppl. 76, 285-290.

74. Yang, Z., Bosco, G., Montante, A., Ou, X., and Camporesi, E. (2001) Hyperbaric O2 reduces intestinal ischemiareperfusion-induced TNF-alpha production and lung neutrophil sequestration. Eur. J. Appl. Physiol. 85, 96-103.

75. Bokeriia, L.A., Frolova, M.A., and Kostava, V.T. (1979) Suppression of humoral antibody synthesis on exposure to hyperbaric oxygenation. Biull. Eksp. Biol. Med. 87(4), 320-322.

76. Keizer, L.S. (1979) Action of oxygen under increased pressure on the neutrophil metabolism in the peripheral blood. Kosm. Biol. Aviakosm. Med. 13(3), 58-61.

77. Hansbrough, J.F., Piacentine, J.G., and Eiseman, B. (1980) Immunosuppression by hyperbaric oxygen. Surgery 87, 662-667.

78. Inamoto, Y., Okuno, F., Saito, K., Tanaka, Y., Watanabe, K., Morimoto, I., Yamashita, U., and Eto, S. (1991) Effect of hyperbaric oxygenation on macrophage function in mice. Biochem. Biophys. Res. Commun. 179, 886-891.

79. Al-Waili, N., Thewani, A., and Al-Azzawi, H. (1980) The Effects of PGA1 on Antibody Production. The World Conference on Clinical Pharmacology and Therapeutics. London. pp 0246.

80. Blair, E., Henning, G., Esmond, W., Attar, S., Cowley, R., and Michaelis, M. (1964) The effect of hyperbaric oxygenation (OHP) on three forms of shock - traumatic, hemorrhagic, and septic. J. Trauma 4, 652-663.

81. Lahat, N., Bitterman, H., Yaniv, N., Kinarty, A., and Bitterman, N. (1995) Exposure to hyperbaric oxygen induces tumour necrosis factor-alpha (TNF-alpha) secretion from rat macrophages. Clin. Exp. Immunol. 102, 655-659.

82. MacKenzie, D., Sollinger, H., and Hullett, D. (2000) Role of CD4+ regulatory T cells in hyperbaric oxygen-mediated immune nonresponsiveness. Hum. Immunol. 61, 1320-1331.

83. Bredt, D. and Snyder, S. (1992) Nitric oxide, a novel neuronal messenger. Neuron 8, 3-11.

84. Garthwaite, J. (1991) Glutamate, nitric oxide and cell-cell signaling in the nervous system. Trends Neurosci. 14, 6067.

85. Richter, C., Gogvadze, V., Schlapbach, R., Schweizer, M., and Schlegel, J. (1994) Nitric oxide kills hepatocytes by mobilizing mitochondrial calcium. Biochem. Biophys. Res. Commun. 205, 1143-1150.

86. Gopalakrishna, R., Chen, Z.H., and Gundimeda, U. (1993) Nitric oxide and nitric oxide generating agents induce a 
reversible inactivation of protein kinase C activity and phorbol ester binding. J. Biol. Chem. 268, 27180-27185.

87. Michetti, M., Salamino, F., Melloni, E., and Pontremoli, S. (1995) Reversible inactivation of calpain isoforms by nitric oxide. Biochem. Biophys. Res. Commun. 207, 1009-1014.

88. Thom, S., Bhopale, V., Fisher, D., Manevich, Y., Huang, P., and Buerk, D. (2002) Stimulation of nitric oxide synthesis in cerebral cortex due to elevated partial pressures of oxygen: an oxidative stress response. J. Neurobiol. 51, $85-100$.

89. Gow, A. and Stamler, J. (1998) Reactions between nitric oxide and haemoglobin under physiological conditions. Nature 391, 169-173.

90. Jia, L., Bonaventura, C., Bonaventura, J., and Stamler, S. (1996) S-nitrosohaemoglobin: a dynamic activity of blood involved in vascular control. Nature 380, 221-226.

91. Thom, S. (1993) Functional inhibition of leukocyte B2 integrins by hyperbaric oxygen in carbon monoxide-mediated brain injury in rats. Toxicol. Appl. Pharmacol. 123, 248-256.

92. Mak, S., Egri, Z., Tanna, G., Colman, R., Newton, G.E. (2002) Vitamin C prevents hyperoxia-mediated vasoconstriction and impairment of endothelium-dependent vasodilation. Am. J. Physiol. Heart Circ. Physiol. 282, $\mathrm{H} 2414-\mathrm{H} 2421$.

93. Cornfield, D., Reeve, L., Tolarova, S., Weir, E., and Archer, S. (1996) Oxygen causes fetal pulmonary vasodilation through activation of a calcium-dependent potassium channel. Proc. Natl. Acad. Sci. U. S. A. 93, 8089-8094.

94. Dweik, R., Laskowski, D., Abu-Soud, H., Kaneko, F., Hutte, R., Stuehr, D., and Erzurum, S. (1998) Nitric oxide synthesis in the lung. J. Clin. Invest. 101, 660-666.

95. Steenbergen, J., Bohlen, H., and Lash, J. (1994) Role of a lymphatic system in glucose absorption and the accompanying microvascular hyperemia. Am. J. Physiol. Gastrointest. Liver Physiol. 267, G529-G535.

96. Bredt, D. and Snyder, S. (1990) Isolation of nitric oxide synthetase, a calmodulin-requiring enzyme. Proc. Natl. Acad. Sci. U. S. A. 87, 682-685.

97. Su, Y. and Block, E. (2000) Role of calpain in hypoxic inhibition of nitric oxide synthase activity in pulmonary endothelial cells. Am. J. Physiol. Lung Cell. Mol. Physiol. 278, L1204-L1212.

98. Benedict, F. and Higgins, H. (1911) Effects on men at rest of breathing oxygen-rich gas mixtures. Am. J. Physiol. 28, $1-28$.

99. Crawford, P., Good, P., Gutierrez, E., Feinberg, J., Boehmer, J., Silber, D., and Sinoway, L. (1997) Effects of supplemental oxygen on forearm vasodilation in humans. J. Appl. Physiol. 82, 1601-1606.

100. Daly, W. and Bondurat, S. (1962) Effects of oxygen breathing on the heart rate, blood pressure and cardiac index of normal men-resting, with reactive hyperemia and after atropine. J. Clin. Invest. 41, 126-132.

101. Ballinger, S., Dorner, G., Wenzel, R., Graselli, U., Findl, O., Eichler, H.G., Wolzt, M., and Schmetterer, L. (2000) Endothelin-1 contributes to hyperoxia-induced vasoconstriction in the human retina. Invest. Ophthalmol. Vis. Sci. 41, 864-869.

102. Mouren, S., Souktani, R., Beaussier, M., Abdenour, L., Arthaud, M., Duvelleroy, M., and Vicaut, E. (1997) Mechanisms of coronary vasoconstriction induced by high arterial oxygen tension. Am. J. Physiol. Heart Circ. Physiol. 272, H67-H75.

103. Pries, A., Heide, J., Ley, K., Klotz, K., and Gaehtgens, P. (1995) Effect of oxygen tension of regulation of arteriolar diameter in skeletal muscle in situ. Microvasc. Res. 49, 289-299.

104. Kahler, J., Mendel, S., Weckmuller, J., Orzechowski, H.D., Mittmann, C., Koster, R., Paul, M., Meinertz, T., and Munzel, T. (2000) Oxidative stress increases synthesis of big endothelin-1 by activation of the endothelin-1 promoter. J. Mol. Cell. Cardiol. 32, 1429-1437.

105. Abu-Soud, M., Rousseau, D., and Stuehr, D. (1996) Nitric oxide binding to the heme of neuronal nitric-oxide synthase links its activity to changes in oxygen tension. J. Biol. Chem. 271, 32515-32518.

106. Knowles, R. and Moncada, S. (1992) Nitric oxide as a signal in blood vessels. Trends Biochem. Sci. 17, $399-402$.

107. Rengasamy, A. and Johns, R. (1991) Characterization of endothelium-derived relaxing factor/nitric oxide synthase from bovine cerebellum and mechanism of modulation by high and low oxygen tensions. J. Pharmacol. Exp. Ther. 259, 310-316.

108. Pedoto, A., Nandi, J., Yang, Z., Wang, J., Bosco, G., Oler, A., Hakim, T., and Camporesi, E. (2003) Beneficial effect of hyperbaric oxygen pretreatment on lipopolysaccharide-induced shock in rats. Clin. Exp. Pharmacol. Physiol. 30, 482-488.

109. Elayan, I.M., Axley, M.J., Prasad, P.V., Ahlers, S.T., and Auker, C.R. (2000) Effect of hyperbaric oxygen treatment on nitric oxide and oxygen free radicals in rat brain. J. Neurophysiol. 83, 2022-2029.

110. Thom, S., Fisher, D., Zhang, J., Bhopale, V.M., Ohnishi, S.T., Kotake, Y., Ohnishi, T., and Buerk, D.G. (2003) Stimulation of perivascular nitric oxide synthesis by oxygen. Am. J. Physiol. Heart Circ. Physiol. 284, H1230-1239.

111. Jamieson, D. and van den Brenk, H. (1963) Measurement of oxygen tensions in cerebral tissues of rats exposed to high pressures of oxygen. J. Appl. Physiol. 18, 869-876.

112. Zhang, J., Sam, A., Klitzman, B., and Piantadosi, C. (1995) Inhibition of nitric oxide synthase on brain oxygenation in anesthetized rats exposed to hyperbaric oxygen. Undersea Hyperb. Med. 22, 377-382.

113. Demchenko, I., Boso, A.E., O'Neill, T., Bennett, P., and Piantadosi, C. (2000) Nitric oxide and cerebral blood flow responses to hyperbaric oxygen. J. Appl. Physiol. 88, 1381-1389.

114. Bergo, G. and Tysebotn, I. (1992) Cerebral blood flow distribution during exposure to 5 bar oxygen in awake rats. 
Undersea Biomed. Res. 19, 339-354.

115. Zhiliaev, S., Moskvin, A., Platonova, T., Gutsaeva, D., Churilina, I., and Demchenko, I. (2002) Hyperoxic vasoconstriction in the brain is realized by inactivation of nitric oxide by superoxide anions. Ross. Fiziol. Zh. Im. I. M. Sechenova 88, 553-559.

116. Demchenko, I., Boso, A., Bennett, P., Whorton, A., and Piantadosi, C. (2000) Hyperbaric oxygen reduces cerebral blood flow by inactivating nitric oxide. Nitric Oxide 4, 597-608.

117. Gow, A., Luchsinger, B., Pawloski, J., Singel, D., and Stamler, J. (1999) The oxyhemoglobin reaction of nitric oxide. Proc. Natl. Acad. Sci. U. S. A. 96, 9027-9032.

118. Gajendrareddy, P.K., Sen, C.K., Horan, M.P., and Marucha, P.T. (2005) Hyperbaric oxygen therapy ameliorates stress-impaired dermal wound healing. Brain Behav. Immun. 19(3), 217-222.

119. Chen, T., Lin, S., Liu, J., Xu, B., Hai, J., and Tang, D. (2002) Effects and mechanism of hyperbaric oxygen on prostaglandins in alveolar bone and gingival of experimental periodontitis in animal. Zhonghua Kou Qiang Yi Xue Za Zhi 37, 228-320.

120. Walker, B., Attallah, A., Lee, J., Hong, S., Mookerjee, B., Share, L., and Krasney, J. (1980) Antidiuresis and inhibition of PGE2 excretion by hyperoxia in the conscious dog. Undersea Biomed. Res. 7, 113-126.

121. Yin, W., Badr, A., Mychaskiw, G., and Zhang, J. (2002) Down regulation of COX-2 is involved in hyperbaric oxygen treatment in a rat transient focal cerebral ischemia model. Brain Res. 926, 165-171.

122. Mialon, P. and Barthelemy, L. (1993) Effect of hyperbaric oxygen on prostaglandin and thromboxane synthesis in the cortex and the striatum of rat brain. Mol. Chem. Neuropathol. 20, 181-189.

123. Rachmilewitz, D., Karmeli, F., Okon, E., Rubenstein, I., and Better, O. (1998) Hyperbaric oxygen: a novel modality to ameliorate experimental colitis. Gut 43, 512-518.

124. Serebrianskaia, M. and Masenko, V. (1993) Dynamics of prostaglandin E content in patients with duodenal ulcer various treatment regimens. Klin. Med. (Mosk.) 71, 45-47.

125. Ersanli, D., Karadayi, K., Toyran, S., Akin, T., Sonmez, M., Ciftci, F., Top, C., and Elbuken, E. (2005) The efficacy of hyperbaric oxygen for the treatment of experimental uveitis induced in rabbits. Ocul. Immunol. Inflamm. 13(5), 383-388.

126. Helms, A.K., Whelan, H.T., and Torbey, M.T. (2005) Hyperbaric oxygen therapy of cerebral ischemia. Cerebrovasc. Dis. 20(6), 417-426.

127. Kiyan, G., Aktas, S., Ozel, K., Isbilen, E., Kotiloglu, E., and Dagli, T.E. (2004) Effects of hyperbaric oxygen therapy on caustic esophageal injury in rats. J. Pediatr. Surg. 39(8), 1188-1193.

128. Tokar, B., Gundogan, A.H., Ilhan, H., Bildirici, K., Gultepe, M., and Elbuken, E. (2003) The effect of hyperbaric oxygen treatment on the inflammatory changes caused by intraperitoneal meconium. Pediatr. Surg. Int. 19(9-10), 673-676.

129. Akin, M.L., Gulluoglu, B.M., Uluutku, H., Erenoglu, C., Elbuken, E., Yildirim, S., and Celenk, T. (2002) Hyperbaric oxygen improves healing in experimental rat colitis. Undersea Hyperb. Med. 29(4), 279-285.

130. Sumen, G., Cimsit, M., and Eroglu, L. (2001) Hyperbaric oxygen treatment reduces carrageenan-induced acute inflammation in rats. Eur. J. Pharmacol. 431(2), 265-268.

131. Loran, O.B., Dunaevskii, Ia.L., Vishnevskii, A.E., and Vashkevich, V.I. (1997) The joint use of hyperbaric oxygenation and EHF therapy in benign prostatic hyperplasia and its combination with chronic prostatitis. Urol. Nefrol. (Mosk.) (2), 32-34.

132. Izawa, K., Tsunoda, T., Ura, K., Yamaguchi, T., Ito, T., Kanematsu, T., and Tsuchiya, R. (1993) Hyperbaric oxygen therapy in the treatment of refractory peripancreatic abscess associated with severe acute pancreatitis. Gastroenterol. Jpn. 28, 284-291.

133. Abdullah, M., AL-Waili, N., Butler, G., and Baban, N. (2006) Hyperbaric oxygen as adjunctive therapy for bilateral compartment syndrome, rhabdomyolysis and acute renal failure after herion intake. Arch. Med. Res., in press.

134. Balkan, A., Balkan, M., Yasar, M., Korkmaz, A., Erdem, O., Kilic, S., Kutsal, O., and Bilgic, H. (2006) Pulmonary protective effects of hyberbaric oxygen and $\mathrm{N}$-acetylcysteine treatment in necrotizing pancreatitis. Physiol. Res. 55(1), $25-31$.

\section{This article should be cited as follows:}

Al-Waili, N.S. and Butler, G.J. (2006) Effects of hyperbaric oxygen on inflammatory response to wound and trauma: possible mechanism of action. TheScientificWorldJOURNAL 6, 425-441. DOI 10.1100/tsw.2006.78. 


\section{BIOSKETCH}

Noori S. Al-Waili, MD, DOG, PhD, CHT, Director of Clinical Research, Life Support Technologies, Inc., Chronic Wound Treatment and Hyperbaric Medicine Center, The Mount Vernon Hospital, Mount Vernon, NY. Dr. Al-Waili is a physician and research scientist who has published more than 160 scientific papers in nephrology, urology, alternative medicine, hypertension, diabetes, malignancy, immunity, and biomedical sciences, including a wide range of new therapeutic measures. He has developed many theories and discoveries in modern and alternative medicine; published in esteemed international scientific journals; published several exciting papers in nephrology/urology including peritoneal macrophages transfusion, enuresis, renal colic, frequency of micturiton, and many papers on hyperbaric medicine and wound care; and more than 40 scientific clinical and laboratory publications on alternative medicine and honey. Presently, his main interest is focused on nephrology/urology, wound care, and hyperbaric medicine, as well as alternative medicine. He serves as an Editorial Board member of several medical journals, a member of evaluator panel, Current Drug, U.K., and a reviewer for many medical and biomedical journals. 


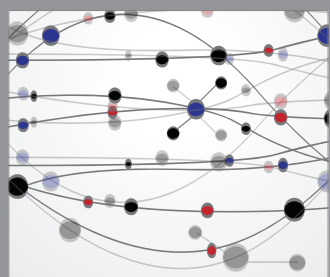

The Scientific World Journal
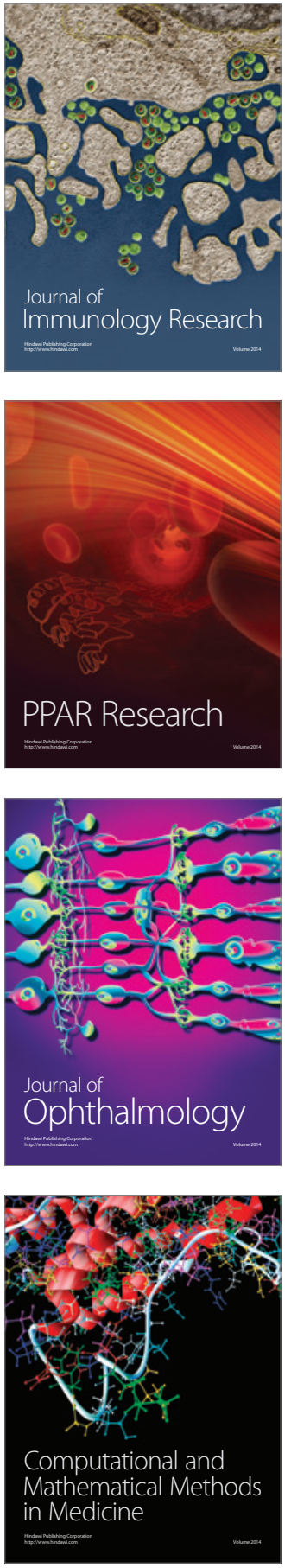

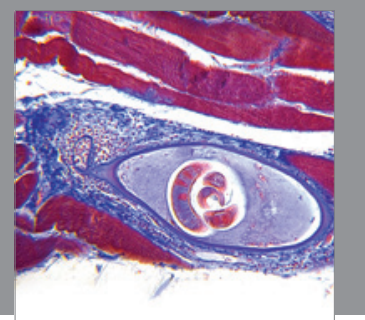

Gastroenterology

Research and Practice
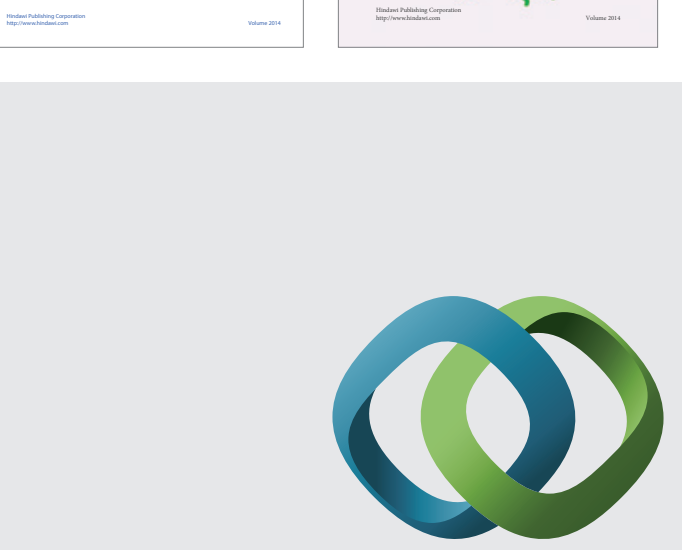

\section{Hindawi}

Submit your manuscripts at

http://www.hindawi.com
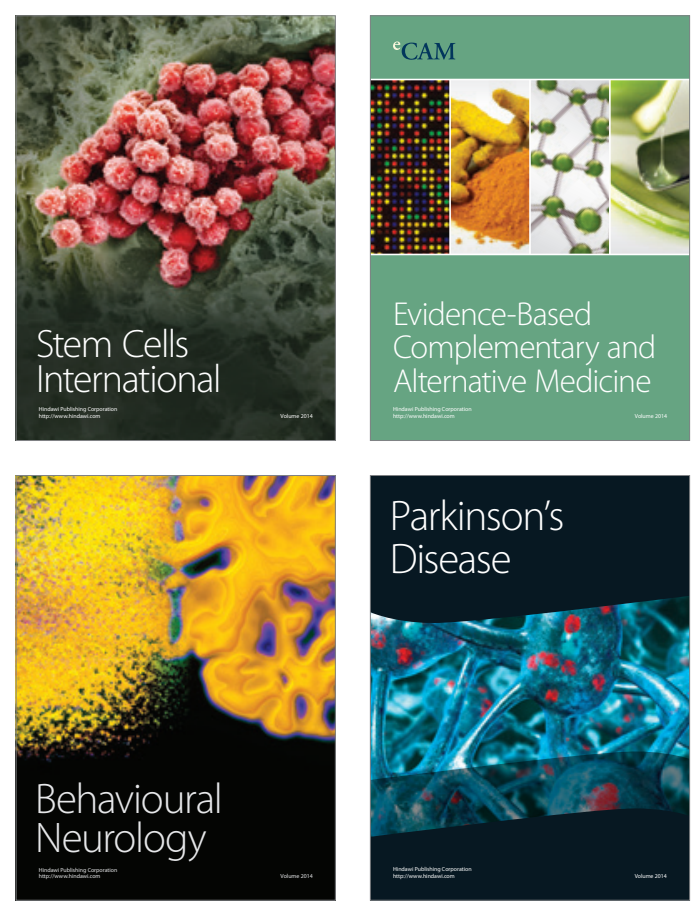

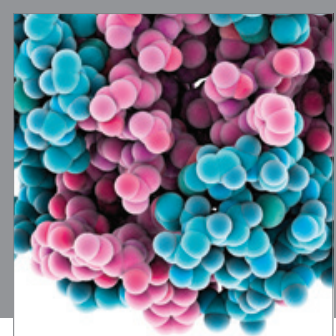

Journal of
Diabetes Research

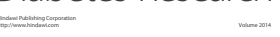

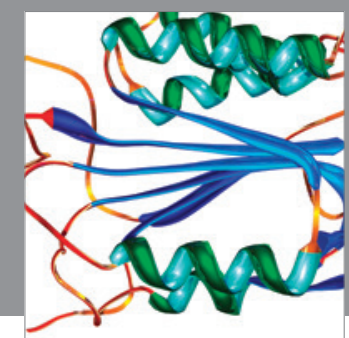

Disease Markers
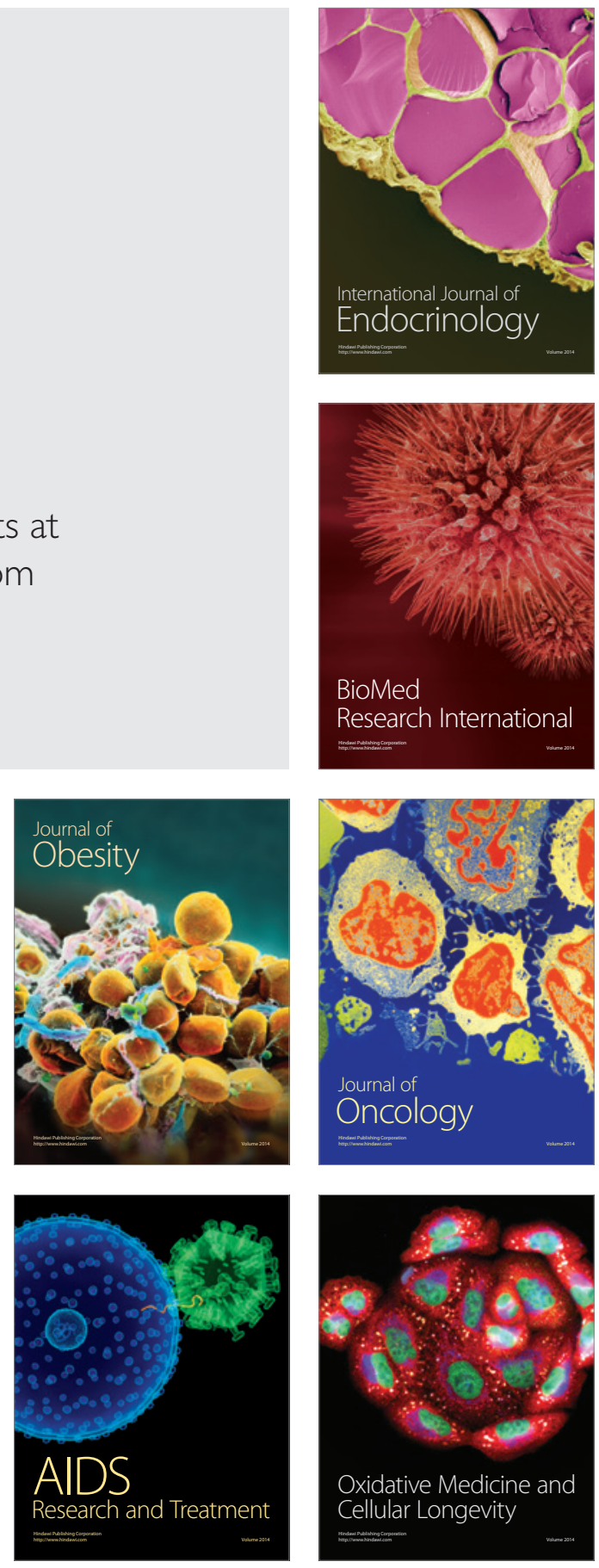